\title{
Editorial
}

\section{Cardiac surgery for the elderly: a surgeon's perspective}

Cardiac surgery is being offered to an ever expanding range of patients. In this regard we are victims of our own success. Cardiac surgery is now routine and as techniques and results have improved, indications have broadened. Whether it is coronary bypass surgery for young diabetic patients awaiting renal transplantation or elderly patients with disabling symptoms of aortic stenosis, a case can be made for each operation.

The problem is that we can only do so much operating with the resources available. How are we to chose between patients? The ethical dilemmas are discussed elsewhere, but from a surgeon's standpoint, what are the issues that spring to mind when considering cardiac surgery in the elderly?

First, are we seeing the tip of the iceberg? Probably. If the paper by Bouma et al from the Netherlands in any way reflects UK practice, ${ }^{1}$ then aortic valve surgery may be being offered to only just over half of those patients $\geqslant 70$ years presenting to cardiologists who fulfill standard criteria for surgery. This despite clear evidence of survival benefit well in excess of that provided by medical management alone. How many other elderly patients were not even referred for assessment?

Second, how will this rising tide of elderly patients affect the running of the surgical unit? The Oxford and Manchester units' experiences ${ }^{23}$ are probably fairly typical. Elderly patients are more likely to be taking up acute hospital beds and requiring urgent surgery. Postoperative use of intensive care facilities is greater because of more frequent complications, and the overall cost is up to $50 \%$ greater than the budgeted cost. In common with other UK centres, $32 \%$ of patients undergoing coronary artery bypass surgery at the new South West Cardiothoracic Surgical Unit in Plymouth were $\geqslant 70$ years in its first year of operation; $54 \%$ of them were classified as urgent and had to remain in hospital pending surgery.

Third, do the results of our endeavours justify the investment? Mortality, morbidity, and quality of life are all valuable end points. There is abundant evidence that quality of life is well maintained or improved in the survivors of coronary and valve surgery in this age group, but there is a price to pay. The Oxford early mortality in the octogenarians undergoing aortic valve surgery was $19 \%$, in addition, $60 \%$ of the cohort suffered one or more serious postoperative complications. The results from Bouma et al and Zaidi et al are more encouraging ${ }^{12}$ but these are younger patients and probably more highly selected.

The referrals for surgery on these elderly patients come thick and fast. The usual introductory phrase sounds something like "I've got this delightful, otherwise fit, sprightly lady who's 80 but looks like 50 who needs her coronaries sorting out." While we sympathise with the dilemma of the patient and her doctors, we are mindful of these wise words of Thibault's discussant who said "There is nothing like cardiac surgery to bring out a patient's true age". ${ }^{4}$ If we groan when we see an 80 year old on our operating list, we do so because we appreciate that the tissues may be poor and the procedure correspondingly more taxing. Procedural imperfections are cruelly punished and the chances of postoperative complications are that much greater. The younger elective patients will have their surgery delayed again by another 80 year old with unstable angina in coronary care and the surgical unit is operating well over budget.

J UNSWORTH-WHITE

Consultant Cardiothoracic Surgeon,

Derriford Hospital, Plymouth PL6 8DH, UK

1 Bouma BJ, van den Brink RBA, van der Meulen JHP, et al. To operate or not on elderly patients with aortic stenosis: the decision and its consequences. Heart 1999;82:143-8.

2 Zaidi AM, Fitzpatrick AP, Keenan DJM, et al. Good outcomes from cardiac surgery in the over 70s. Heart 1999;82:134-7.

3 Gilbert T, Orr W, Banning AP. Surgery for aortic stenosis in severely symptomatic patients older than 80 years of age: experience in a single UK centre. Heart 1999;82:138-42.

4 Thibault GE. Too old for what? N Engl f Med 1993;328:946-50. 